\title{
Consumo crónico de olmesartán como causa de enteropatía "sprue-like":
}

\author{
Alberto López-Serrano ${ }^{1}$, Antonio Martínez-Egea ${ }^{2}$, Raquel Laveda Cano ${ }^{2}$, Juan Manuel Arriero Marín ${ }^{3}$, \\ María Jose Mayol Belda ${ }^{4}$, Pablo Roig Rico ${ }^{1}$
}

Resumen: La diarrea es un efecto secundario habitual a la toma de fármacos, y en algunas ocasiones la enteropatía perdedora de proteínas tipo "sprue like" puede estar detrás de esta patología. El estudio de esta enfermedad puede suponer un desafío importante para el clínico, sobre todo en los casos que cursan con serología negativa para enfermedad celiaca. La atrofia vellositaria duodenal secundaria a la ingesta de micofenolato-mofetil y metotrexate es bien conocida y descrita desde hace tiempo, pero desde la inclusión en la posológica habitual de olmesartán como antihipertensivo de primera elección hemos objetivado un repunte importante de esta entidad. Debido al amplio uso de esta medicación, queremos poner de manifiesto esta enteropatía iatrogénica a través de dos casos clínicos ocurridos en nuestro hospital en 2014.

Palabras clave: Diarrea; Enteropatia; Atrofia vellositaria; olmesartán; sprue-like; celiaco; insuficiencia renal aguda.

Abstract: Diarrhea is a common side effect of medical treatment. "Sprue like" enteropathy may be behind this pathology. The study of this disease can be an important clinical challenge, especially in those cases with negative serology for celiac disease. Duodenal villous atrophy secondary to the intake of mycophenolate mofetil and methotrexate have been well known and described but since the inclusion of olmesartán as a first-line antihypertensive, we have seen an important rebound of this entity. Due to the wide use of this medication we want to report this iatrogenic effect through two clinical cases that occurred in our hospital in 2014.

Keywords: Diarrhea; Enteropathy; Villous atrophy; Olmesartan; Sprue-like; Celiac; Acute renal failure.

Fecha de envío: 28 de octubre de 2016 - Fecha de aceptación: 13 de marzo de 2017

\section{Introducción}

Los procesos diarreicos como efecto secundario farmacológico son muy frecuentes en la práctica clínica habitual, si bien los mecanismos patogénicos por los que se producen no son bien conocidos en la mayoría de los casos.

La enteropatía perdedora de proteínas tipo "sprue like" puede estar detrás de estos procesos. El estudio de esta enfermedad puede suponer un desafío importante para el clínico, sobre todo en los casos que cursan con serología negativa para enfermedad celiaca. El diagnóstico diferencial incluirá patologías diversas como el sobrecrecimiento bacteriano, infecciones por parásitos intestinales, linfoma intestinal de células T, sprue tropical, sprue colágeno y la asociada a fármacos (De Gaetani et al., 2013).
La atrofia vellositaria duodenal secundaria a la ingesta de micofenolato-mofetil y metotrexate es bien conocida y descrita desde hace tiempo. En los últimos años se han descrito casos similares en relación al consumo de fármacos antihipertensivos, concretamente ARA II (antagonistas del receptor de angiotensina II), y más específicamente, olmesartán (Esteve et al., 2016; laniro et al.,2014).

Nuestro objetivo es notificar dos casos clínicos de enteropatía severa relacionada con la toma de olmesartán, demostrada por la supresión de la clínica tras la retirada del fármaco.

(1) Servicio de Medicina Interna H.U. San Juan de Alicante

(2) Servicio Medicina Digestiva H.U. San Juan de Alicante

(3) Jefe de Estudios H.U. San Juan de Alicante

(4) Servicio de Anatomia Patológica, H.U. San Juan de Alicante

Autor de correspondencia: loseal88@gmail.com 


\section{Casos clínicos}

Caso 1: mujer de 80 años de edad con antecedentes de HTA (hipertensión arterial), dislipemia, síndrome de Meniere en tratamiento con betahistina, y carcinoma de ovario diagnosticado en 2009, estadio I-C (FIGO), intervenido quirurgicamente mediante histerectomía + anexectomía bilateral, actualmente sin recaídas en seguimiento por ginecología. En tratamiento con olmesartán/ amlodipino/hidroclorotiacida 40/5/12.5 desde hacía 20 meses y lovastatina $20 \mathrm{mg}$. La paciente acudió al servicio de urgencias de nuestro hospital en repetidas ocasiones, por diarrea persistente sin productos patológicos de hasta 20 deposiciones diarias, asociada a náuseas, vómitos y pérdida de unos $10 \mathrm{Kg}$ de peso. El cuadro diarreico se asociaba a un importante deterioro del estado general, con hipotensión, insuficiencia renal aguda concomitante (creatinina 3,3 mg/dL), acidosis metabólica (pH: 7,15; HCO3: 16,5 $\mathrm{mEq} / \mathrm{L}$ ), e hipoalbuminemia de $2,1 \mathrm{~g} / \mathrm{dl}$ (proteínas totales 5,2 gr/dl). En un primer momento se inició tratamiento con fluidoterapia y ciprofloxacino con resolución completa de la clínica en las primeras 48 horas. Las pruebas complementarias incluyendo colonoscopia, entero-RMN (Resonancia Magnética Nuclear), coprocultivos, toxina y PCR de C. Difficile fueron inespecíficas o negativas. A los 7 días del alta hospitalaria y tras reiniciar medicación habitual, reingresa en el servicio de Medicina Digestiva por misma sintomatología por lo que se completó estudio mediante gastroscopia, sin objetivar hallazgos macroscópicos significativos. En las biopsias seriadas de duodeno se evidenció una duodenitis erosiva con atrofia vellositaria severa, compatible con síndrome "sprue-like". Durante su ingreso se descartó de forma razonable enfermedad celiaca (anticuerpos anti transglutaminasa-lgA, antigliadina negativos (IgA de 240 mg/ $\mathrm{dL}$ ), linfoma intestinal (inmunohistoquímica de biopsia duodenal negativa), así como enteritis infecciosa (coprocultivos, toxina y PCR para Clostridium difficile negativos). Debido a la relación entre la reintroducción del fármaco antihipertensivo y el empeoramiento clínico, valoramos la posibilidad de que la enteropatía pudiera ser consecuencia directa del consumo de olmesartán. El diagnóstico al alta fue el de probable enteropatía con atrofia severa vellositaria secundaria a la toma de olmesartán. A los 6 meses de la retirada del fármaco se realizaron nuevas biopsias duodenales mediante gastroscopías, mostrando resolución completa de la importante atrofia vellositaria previa.

Caso 2: mujer de 76 años con antecedentes personales de hipertensión arterial, diabetes mellitus tipo 2 insulino dependiente, dislipemia, y cardiopatía isquémica crónica de 14 años de evolución. En tratamiento con repaglinida, insulina detemir, olmesartán/ amlodipino a dosis de 40/10 mg, ácido acetil salicílico (AAS) 100 mg, y nebivolol $5 \mathrm{mg} /$ día. Ingresada en la unidad de enfermedades infecciosas en 2 ocasiones por diarrea persistente de 15 días de evolución, sin productos patológicos, ni fiebre asociada. Clínicamente destacaba una importante deshidratación cutáneomucosa, así como tensión arterial de 85/40 mmHg. Durante su primer ingreso se inició tratamiento con ceftriaxona retirándose la medicación antihipertensiva. Si bien no hubo repercusión sobre el filtrado glomerular, el grado de hipoalbuminemia fue moderado-severa $(1,7 \mathrm{~g} / \mathrm{dL})$. Se realizó colonoscopía sin hallazgos patológicos. El cultivo de heces resultó positivo para Salmonella sp, por lo que se dio de alta como gastroenteritis secundaria a salmonella. Tras la introducción del tratamiento habitual, y como en el caso anterior, reapareció la misma sintomatología reingresando en el servicio de Medicina Digestiva. Se descartó enfermedad celiaca con serología negativa (anticuerpos antigliadina y antitransglutaminasa con IgA en rango normal), siendo los coprocultivos positivos para Aeromonas $s p$ y negativos para parásitos. Debido al ingreso prolongado y a la toma de antibióticos, se realizó toxina y PCR de Clostridium difficile en heces que resultó negativa. Tras realizar gastroscopía, la biopsia duodenal objetivó duodenitis con importante atrofia vellositaria. Al alta, la paciente permanecía asintomática tras completar antibioterapia con ceftriaxona y retirada de olmesartán. Ante la intermitencia de los síntomas y su asociación con la toma del fármaco, se relacionó la enteropatía con la toma de olmesartán, confirmándose en los 6 meses posteriores con la reepitelización vellositaria en la gastroscopia de control. Actualmente la paciente permanece asintomática.

\section{Discusión}

La enteropatía "sprue-like" secundaria a olmesartán es una patología a tener en cuenta en el diagnóstico diferencial de las diarreas persistentes o crónicas. Debido a la fisiopatología de la enfermedad, la clínica no se produce inmediatamente después de la introducción del fármaco, sino que es necesaria la alteración del epitelio duodenal a lo largo de meses o incluso años (De Gaetani et al., 2013; Esteve et al., 2016).

El sustrato por el que se produce esta patología es desconocido en el momento actual (Rubio-Tapia et al., 2012).

Se ha descrito en la literatura inhibición del factor beta de crecimiento $\beta$ (TGF- $\beta$ ) por parte de los inhibidores del receptor de angiotensina II (especialmente en procesos como la proliferación de la célula mesangial glomerular y el síndrome de Marfan) (Kagami et al., 1994).

Se desconoce si este mecanismo puede relacionarse con la aparición de la atrofia vellositaria duodenal. Dentro de la clínica característica de este tipo de diarrea, hay que hacer hincapié en la reaparición de los síntomas con la reintroducción del fármaco, que se suele retirar ante la hipotensión sintomática e insuficiencia renal aguda que supone la importante deshidratación asociada. Por este 
motivo, la remisión clínica y analítica suele ser muy rápida, entre 24 y 48 horas tras el ingreso. En algunos casos la enteritis infecciosa nosocomial o asociada a cuidados sanitarios, puede ser un factor de confusión, como ocurrió en el segundo de los casos presentados, a pesar de que la paciente en ningún momento presentó fiebre durante ambos ingresos. También cabría destacar la posibilidad de la enteropatia autoinmune dentro del diagnóstico diferencial de la patología, sobre todo cuando se asocia con signos clínicos extraintestinales (exantema cutáneo, artralgias, espondiloartritis, aftas orales,...). Olmesartán es un antihipertensivo de primera elección, sobre todo en enfermos con hipertensión refractaria y diabéticos, por lo que la incidencia de esta patología se prevé en aumento en los próximos años. Organismos internacionales como la FDA ha comunicado varias alertas sobre esta toxicidad en marzo de 2013 así como de metotrexato y azatioprina anteriormente (Food and Drug Administration, 2013). Por lo tanto, la enteritis "sprue-like" de causa farmacológica, y más concretamente la debida a olmesartán, debe tenerse especialmente en cuenta dentro del diagnóstico diferencial del síndrome diarreico crónico con serología negativa para enfermedad celiaca o ante la ausencia de mejoría tras la retirada del gluten. La toma crónica de olmesartán, la presencia de una biopsia duodenal con importante atrofia vellositaria, así como la mejoría de la clínica tras suprimir el fármaco, deberían ser suficientes argumentos para el diagnóstico de esta enfermedad; si bien la comprobación de la reepitelización duodenal mediante biopsia duodenal a los 3-6 meses debe valorarse individualmente, siendo controvertida en pacientes con mejoría clínica evidente tras retirada del fármaco. En casos de enteropatia perdedora de proteínas secundaria a olmesartán, se recomienda sustituir la terapia antihipertensiva por otros antagonistas del receptor de angiotensina II, inhibidores de la encima convertidora de angiotensina o calcio-antagonistas.

\section{Referencias}

DeGaetani M, Tennyson CA, Lebwohl B, Lewis SK, Abu Daya H, Arguelles-Grande C, Bhagat G \& Green PH. (2013). Villous atrophy and negative celiac serology: a diagnostic and therapeutic dilemma. The American journal of gastroenterology 108, 647-653.

Esteve M, Temino R, Carrasco A, Batista L, Del Val A, Ble M, Santaolaria S, Molina-Infante J, Soriano G, Agudo S, Zabana Y, Andujar $X$, Aceituno M, Ribes J, Madridejos R \& Fernandez-Banares F. (2016). Potential coeliac disease markers and autoimmunity in olmesartan induced enteropathy: A population-based study. Digestive and liver disease: official journal of the Italian Society of Gastroenterology and the Italian Association for the Study of the Liver 48, 154-161.

laniro G, Bibbo S, Montalto M, Ricci R, Gasbarrini A \& Cammarota G. (2014). Systematic review: Sprue-like enteropathy associated with olmesartan. Alimentary pharmacology \& therapeutics 40, 16-23.

Kagami S, Border WA, Miller DE \& Noble NA. (1994). Angiotensin II stimulates extracellular matrix protein synthesis through induction of transforming growth factor-beta expression in rat glomerular mesangial cells. Journal of Clinical Investigation 93, 2431-2437.

Rubio-Tapia A, Herman ML, Ludvigsson JF, Kelly DG, Mangan TF, Wu TT \& Murray JA. (2012). Severe spruelike enteropathy associated with olmesartan. Mayo Clinic proceedings 87, 732-738.

U.S. Food and Drug Administration. (2013) Olmesartán Medoxomil: Drug Safety Communication - Label Changes To Include Intestinal Problems (Sprue-Like Enteropathy). 